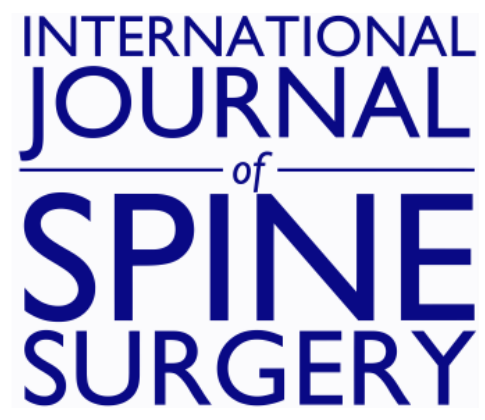

\title{
Prevalence and Factors Affecting Cervical Deformity in Adolescent Idiopathic Scoliosis Patients: A Single-Center Retrospective Radiological Study
}

XIAOBANG HU and ISADOR H. LIEBERMAN

Int J Spine Surg 2018, 12 (1) 22-25

doi: https://doi.org/10.14444/5004

http://ijssurgery.com/content/12/1/22

This information is current as of April 26, 2023.

Email Alerts Receive free email-alerts when new articles cite this article. Sign up at:

http://ijssurgery.com/alerts

The International Journal of Spine Surgery

2397 Waterbury Circle, Suite 1,

Aurora, IL 60504, Phone: +1-630-375-1432 


\title{
Prevalence and Factors Affecting Cervical Deformity in Adolescent Idiopathic Scoliosis Patients: A Single-Center Retrospective Radiological Study
}

\author{
XIAOBANG HU, PhD, ISADOR H. LIEBERMAN, MD, MBA, FRCSC \\ Scoliosis and Spine Tumor Center, Texas Back Institute, Texas Health Presbyterian Hospital, Plano, Texas
}

\begin{abstract}
Background: It has been reported that adult spinal deformity patients have a high prevalence of cervical kyphosis (CK) and cervical positive sagittal malalignment (CPSM). However, the prevalence and possible factors affecting CK and CPSM in patients with adolescent idiopathic scoliosis (AIS) are less clear.

Methods: We retrospectively analyzed a consecutive series of AIS patients from a single center. Radiographic measurements included the Cobb angle, C2-C7 sagittal vertical axis (C2-C7SVA), and C2-C7 lordosis. Cervical deformity was defined as loss of lordotic or neutral cervical angle (CK) or C2-C7SVA more than $4 \mathrm{~cm}$ (CPSM). Patients were stratified by the degree of thoracic kyphosis and coronal thoracic curve.

Results: A total of 99 patients were included in this study. The patients' mean age was 14 years (range, 10-18 years). Mean cervical lordosis and C2-C7SVA were $1.5^{\circ}$ and $30.4 \mathrm{~mm}$, respectively. The CK and CPSM prevalence were $49 \%$ and $16 \%$, respectively, and prevalence of CK and/or CPSM was $59 \%$. CK was present in $32 \%$ of the patients who had $>20^{\circ}$ thoracic kyphosis, and it was present in $75 \%$ of the patients who had $\leq 20^{\circ}$ thoracic kyphosis $(P=.003)$. No association between CPSM and thoracic kyphosis was found. The patients who had $>20^{\circ}$ coronal thoracic curve had higher CK prevalence (64\% versus $37 \%, P=.05)$, but no CPSM association was found.

Conclusions: Cervical deformity is highly prevalent in AIS patients. There is a significant correlation between the loss of thoracic kyphosis and the development of CK but not the development of CPSM. High coronal thoracic curve is associated with CK prevalence, but it is not associated with CPSM prevalence.
\end{abstract}

Other \& Special Categories

Keywords: cervical deformity, adolescent idiopathic scoliosis, prevalence

\section{INTRODUCTION}

In humans, an optimal spinal balance helps to maintain the gravity line in an economic range that is also known as the cone of economy. ${ }^{1}$ An adequate trunk balance in erect position also helps to align the head over the femoral heads and to sustain a horizontal visual gaze. ${ }^{2}$ Adolescent idiopathic scoliosis (AIS) is recognized as a complex 3-dimensional deformation of the spine with lateral deviation in the coronal plane, alteration of the kyphosis/lordosis in the sagittal plane, and rotation of the vertebrae in the axial plane. It has been reported ${ }^{3}$ that there is a significant correlation between the loss of thoracic kyphosis and the development of cervical kyphosis (CK) in AIS patients. The development of cervical kyphosis in AIS patients may represent a compensatory measure from the thoracolumbar deformity.

The need to understand regional as well as global spinal alignment is increasingly recognized by spine surgeons. In adult deformity patients, sagittal malalignment has been demonstrated as a significant source of pain and disability. Recently, Smith et $\mathrm{al}^{4}$ reported that cervical deformity (cervical kyphosis [CK] and cervical positive sagittal malalignment [CPSM]) are highly prevalent in adult patients with thoracolumbar deformity. However, the prevalence of CK and CPSM and possible factors affecting CK and CPSM in AIS patients are less clear. Our objective in this study is to assess the prevalence and possible factors affecting cervical deformity in a series of AIS patients.

\section{MATERIALS AND METHODS \\ Patients}

After institutional review board approval, a single center's database was retrospectively reviewed to identify all the AIS patients who were followed 
Table 1. Demographics of the patients.

\begin{tabular}{lc}
\hline Patients, N & 99 \\
Mean age, y (range) & $14(10-18)$ \\
Gender, female:male & $76: 23$ \\
Cobb angle & \\
MT, mean ${ }^{\circ}$ (range) & $36.3(12-92)$ \\
TL/L, mean ${ }^{\circ}$ (range) & $25.5(6-71)$ \\
\hline
\end{tabular}

Abbreviations: MT, main thoracic; TL/L, thoracolumbar/lumbar.

between May 2010 and March 2014. Preoperative standing anterior-posterior and lateral radiographs and left and right side bending radiographs were reviewed. Coronal and sagittal curves were measured using the Cobb method. Flexibility of the thoracic and lumbar scoliotic curves was assessed from standing and bending radiographs.

\section{Radiographic Measurements}

Radiographic data collection consisted of fulllength standing coronal and sagittal radiographs obtained in free-standing posture. All images were downloaded from picture archiving and communication systems (Digital Imaging and Communications in Medicine format) and analyzed using validated software (Surgimap, Nemaris, New York, New York). Measurements include coronal Cobb angle, C2-C7 sagittal vertical axis (C2-C7SVA), and C2-C7 sagittal Cobb angle ("-" values mean lordosis and "+" values mean kyphosis). Cervical deformity was defined as cervical lordosis more than $0^{\circ}(\mathrm{CK})$ or C2-C7SVA equal to or more than $4 \mathrm{~cm}$ (CPSM). All measurements were performed by an independent researcher. Patients were stratified by the degree of thoracic kyphosis and coronal thoracic curve.

\section{Statistical Analysis}

Descriptive statistics, including means and standard deviations, were calculated for continuous variables. Nominal variables were analyzed using a $\chi^{2}$ test. The Student $t$ test was used for quantitative

Table 2. Prevalence of CK and CPSM.

\begin{tabular}{cc}
\hline SCA (sagittal cervical angle) & \\
Lordosis, n $(\%)$ & $47(47 \%)$ \\
Neutral, n $(\%)$ & $3(3 \%)$ \\
Kyphosis, n $(\%)$ & $49(49 \%)$ \\
C2-C7SVA & \\
Mean (range) & $30.4 \mathrm{~mm}(4-55 \mathrm{~mm})$ \\
$<40 \mathrm{~mm}, \mathrm{n}(\%)$ & $83(84 \%)$ \\
$\geq 40 \mathrm{~mm}, \mathrm{n}(\%)$ & $16(16 \%)$ \\
\hline
\end{tabular}

Abbreviations: CK, cervical kyphosis; CPSM, cervical positive sagittal malalignment.
Table 3. The relationship between cervical kyphosis (CK), cervical positive sagittal malalignment (CPSM), and thoracic kyphosis.

\begin{tabular}{lccc}
\hline & $\begin{array}{c}\text { Thoracic } \\
\text { Kyphosis }>\mathbf{2 0}^{\circ}\end{array}$ & $\begin{array}{c}\text { Thoracic } \\
\text { Kyphosis } \leq \mathbf{2 0 ^ { \circ }}\end{array}$ & $\boldsymbol{P}$ Value \\
\hline CK & $32 \%$ & $75 \%$ & .003 \\
CPSM & $20 \%$ & $14 \%$ & $>.05$ \\
\hline
\end{tabular}

variables and the level of significance was set at $P \leq$ .05 .

\section{RESULTS}

A total of 99 patients were included in this study. The patients' mean age was 14 years (range, 10-18 years). There were 76 girls and 23 boys (Table 1 ). Forty-seven patients $(47 \%)$ had cervical lordosis and their mean cervical lordosis angle was $-10.1^{\circ}$ (range, $-1^{\circ}$ to $\left.-30^{\circ}\right)$. Three patients $(3 \%)$ had a neutral cervical angle $\left(0^{\circ}\right)$. Forty-nine patients $(49 \%)$ had cervical kyphosis and their mean cervical kyphosis angle was $12.8^{\circ}$ (range, $1^{\circ}$ to $50^{\circ}$ ). The patients' mean C2-C7SVA was $30.4 \mathrm{~mm}$. Eightythree patients $(84 \%)$ had a C2-C7SVA less than 40 $\mathrm{mm}$. Sixteen patients $(16 \%)$ had a C2-C7SVA equal to or more than $40 \mathrm{~mm}$ (CPSM). The prevalence of CK and/or CPSM was 59\% (Table 2).

CK was present in $32 \%$ of the patients who had $>20^{\circ}$ thoracic kyphosis; it was present in $75 \%$ of the patients who had $\leq 20^{\circ}$ thoracic kyphosis $(P=.003)$. No association between CPSM and thoracic kyphosis was found $(20 \%$ versus $14 \%, P>.05$; Table 3$)$.

CK was present in $64 \%$ of the patients who had $>20^{\circ}$ coronal thoracic curve, and it was present in $37 \%$ of the patients who had $<20^{\circ}$ or no coronal thoracic curve $(P=.05)$. Meanwhile, no association between CPSM and coronal thoracic curve was found $(19 \%$ versus $13 \%, P>.05$; Table 4$)$.

\section{DISCUSSION}

Normal cervical lordosis is reported to be between $-6.6^{\circ}$ and $-22.2^{\circ}$ in typically developed adults. ${ }^{5}$ The range of cervical lordosis in typically developing adolescents has not been reported, but it has been found that there is a trend of increasing cervical lordosis with age. ${ }^{6}$ In 1995, Hilibrand et al ${ }^{3}$

Table 4. The relationship between cervical kyphosis (CK), cervical positive sagittal malalignment (CPSM), and coronal thoracic curve.

\begin{tabular}{lccr}
\hline & $\begin{array}{c}\text { Coronal Thoracic } \\
\text { Curve }>\mathbf{2 0}^{\circ}\end{array}$ & $\begin{array}{c}\text { Coronal Thoracic } \\
\text { Curve }<\mathbf{2 0}^{\circ}\end{array}$ & $\boldsymbol{P}$ Value \\
\hline CK & $64 \%$ & $37 \%$ & .05 \\
CPSM & $19 \%$ & $13 \%$ & $>.05$ \\
\hline
\end{tabular}


studied the sagittal alignment of the cervical spine in 38 AIS patients and found that $89 \%$ of them had a straightened or kyphotic cervical spine alignment. They also noticed that there was a significant correlation between the loss of thoracic kyphosis and the development of cervical kyphosis for the entire group. Subsequently, Canavese et al ${ }^{7}$ confirmed the high incidence of reduced cervical lordosis in AIS patients, with $34.4 \%$ of their patients having an average cervical kyphosis of $11^{\circ}$. In the current study we found that $49 \%$ of our patients had $\mathrm{CK}$, which is consistent with these previous reports. We also found that the incidence of $\mathrm{CK}$ is significantly higher in those patients whose thoracic kyphosis curves are less than $20^{\circ}$. This is also consistent with the previous finding by Hilibrand et $\mathrm{al}^{3}$

Other than the sagittal cervical angle, another cervical radiographic parameter that has been reported is C2-C7 sagittal vertical alignment (C2C7SVA). Tang et $\mathrm{al}^{8}$ found that in adults, there is a significant correlation between C2-C7SVA and neck disability index scores, with a threshold C2C7SVA value of approximately $40 \mathrm{~mm}$. Smith et $\mathrm{al}^{4}$ studied the prevalence of cervical deformity in 470 adults with thoracolumbar deformity and found that CPSM was present in $29 \%$ of the patients. The threshold value for abnormal C2C7SVA in adolescents has not been reported. Park et $\mathrm{al}^{6}$ assessed the effect of age on cervical sagittal alignment in 100 asymptomatic participants and found that C2-C7SVA does not differ significantly on the basis of age. Thus, in this study we choose to define CPSM in these AIS patients as C2C7SVA equal to or more than $4 \mathrm{~cm}$. In this series, $16 \%$ of the patients were found to have CPSM. The lower prevalence of CPSM and higher prevalence of $\mathrm{CK}$ in young patients with such a deformity may due to the fact that they have more flexible spines that are able to better compensate the thoracolumbar deformity. ${ }^{4}$ Meanwhile, we found that unlike $\mathrm{CK}$, there is no association between CPSM and thoracic kyphosis. Together, our data may imply that the compensatory maneuver for loss of thoracic kyphosis is loss of cervical lordosis in an effort to maintain a neutral and balanced sagittal vertical axis.

We further studied the relationship between CK and/or CPSM prevalence and the patients' coronal thoracic curves. We found that the patients who had $>20^{\circ}$ coronal thoracic curve had higher $\mathrm{CK}$ prevalence but no CPSM association was found. It has been reported ${ }^{4}$ that adult scoliosis patients, especially those who have thoracic scoliosis, have a high prevalence of CK. Although these cervical deformities are not necessarily symptomatic in AIS patients, our findings do suggest that a cervical deformity evaluation should be included in the assessment of thoracolumbar deformity. However, further studies will be needed to define the clinical significance of the high prevalence of cervical deformity in these young patients.

There are also limitations in our study. We did not collect the data regarding the patients' symptoms in this series, and it is not clear if there is a relationship between cervical deformity and the patients' clinical symptoms.

In conclusion, our study shows that cervical deformity is highly prevalent in AIS patients. There is a significant correlation between the loss of thoracic kyphosis and the development of CK but not the development of CPSM. A high coronal thoracic curve is associated with CK prevalence, but it is not associated with CPSM prevalence. Our finding suggests that adolescents have more ability to compensate and maintain a neutral sagittal vertical axis compared with adults. Further study is needed to define the potential clinical significance of cervical deformity in AIS patients.

\section{REFERENCES}

1. Dubousset J. Three-dimensional analysis of the scoliosis deformity. In: Weinstein S, ed. The Pediatric Spine: Principles and Practice. New York, NY: Raven; 1994:479-496.

2. Abelin-Genevois K, Idjerouidene A, Roussouly P, et al. Cervical spine alignment in the pediatric population: a radiographic normative study of 150 asymptomatic patients. Eur Spine J. 2014;23(7):1442-1448.

3. Hilibrand AS, Tannenbaum DA, Graziano GP, et al. The sagittal alignment of the cervical spine in adolescent idiopathic scoliosis. J Pediatr Orthop. 1995;15(5):627-632.

4. Smith JS, Lafage V, Schwab FJ, et al. Prevalence and type of cervical deformity among 470 adults with thoracolumbar deformity. Spine (Phila Pa 1976). 2014;39(17):E1001E1009.

5. Charles YP, Sfeir G, Matter-Parrat V, et al. Cervical sagittal alignment in idiopathic scoliosis treated by posterior instrumentation and in situ bending. Spine (Phila Pa 1976). 2015;40(7):E419-E427.

6. Park MS, Moon SH, Lee HM, et al. The effect of age on cervical sagittal alignment: normative data on 100 asymptomatic subjects. Spine (Phila Pa 1976). 2013;38(8):E458-E463.

7. Canavese F, Turcot K, De Rosa V, et al. Cervical spine sagittal alignment variations following posterior spinal fusion and instrumentation for adolescent idiopathic scoliosis. Eur Spine J. 2011;20(7):1141-1148. 
8. Tang JA, Scheer JK, Smith JS, et al. The impact of standing regional cervical sagittal alignment on outcomes in posterior cervical fusion surgery. Neurosurgery. 2012;71(3):662669; discussion 669 .

Disclosures and COI: The authors declare that there is no direct conflict of interest associated with this manuscript. No funds were received in support of this work.

Corresponding Author: Isador H. Lieberman, MD, MBA, FRCSC, Scoliosis and Spine
Tumor Center, Texas Back Institute, Texas Health Presbyterian Hospital, 6020 West Parker Road, Suite 200a, Plano, TX 75093. Phone: (972) 6085001; Fax: (972) 608-5028; Email: ilieberman@ texasback.com.

Published 30 March 2018

This manuscript is generously published free of charge by ISASS, the International Society for the Advancement of Spine Surgery. Copyright $\odot 2018$ ISASS. To see more or order reprints or permissions, see http://ijssurgery.com. 